\title{
Milk Odd- and Branched-Chain Fatty Acids in Relation to the Rumen Fermentation Pattern
}

\author{
B. Vlaeminck, ${ }^{\star}$ V. Fievez, ${ }^{\star 1}$ S. Tamminga, $†$ R. J. Dewhurst,$\ddagger^{2}$ A. van Vuuren, $\S$ \\ D. De Brabander,\# and D. Demeyer* \\ *Laboratory for Animal Nutrition and Animal Product Quality, Ghent University, Proefhoevestraat 10, 9090 Melle, Belgium \\ †Animal Nutrition Group, Wageningen University, PO Box 338, 6700AH Wageningen, The Netherlands \\ †Institute of Grassland and Environmental Research, Plas Gogerddan, Aberystwyth, Ceredigion SY23 3EB, UK \\ §Animal Sciences Group, Wageningen University, Edelhertweg 15, 8200 AB Lelystad, The Netherlands \\ \#Department of Animal Nutrition and Husbandry, Ministry of the Flemish Community-Agricultural Research Centre, \\ Scheldeweg 68, 9090 Melle, Belgium
}

\section{ABSTRACT}

The objectives of this study were 1) to determine whether a relationship exists between molar proportions of volatile fatty acids in the rumen and milk oddand branched-chain fatty acid concentrations (i.e., iso $\mathrm{C} 13: 0$, anteiso $\mathrm{C} 13: 0$, iso $\mathrm{C} 14: 0, \mathrm{C} 15: 0$, iso $\mathrm{C} 15: 0$, anteiso $\mathrm{C} 15: 0$, iso $\mathrm{C} 16: 0$, C17:0, iso C17:0, anteiso C17:0, and cis-9 C17:1); and 2) to evaluate the accuracy of prediction of the latter equations using an independent data set. For development of the regression equations, individual cow data from 10 feeding experiments with rumen-fistulated dairy cows were used, resulting in a data set of 148 observations. Milk odd- and branched-chain fatty acids were closely related to the molar proportions of acetate $(\mathrm{SE}=15.3 \mathrm{mmol} / \mathrm{mol})$, propionate $(\mathrm{SE}=14.7$ $\mathrm{mmol} / \mathrm{mol}$ ), and butyrate $(\mathrm{SE}=9.2 \mathrm{mmol} / \mathrm{mol})$. These regression equations were further validated using data from the literature $(\mathrm{n}=14)$. Evaluation of these prediction equations using the independent data set resulted in a root mean square prediction error of 3.0, 9.0, and $8.9 \%$ of the observed mean for acetate, propionate, and butyrate, respectively. In addition, less then $5 \%$ of the mean square prediction error was due to line bias. This suggests that the currently developed prediction equations based on milk odd- and branched-chain fatty acids show potential to predict molar proportions of individual volatile fatty acids in the rumen.

Key words: rumen fermentation, volatile fatty acid, milk odd- and branched-chain fatty acids

\section{INTRODUCTION}

The ruminal microbiota form the key link between the ruminant and its diet because VFA and microbial

\footnotetext{
Received February 20, 2006.

Accepted May 22, 2006.

${ }^{1}$ Corresponding author: veerle.fievez@UGent.be

${ }^{2}$ Current address: Agriculture and Life Sciences Division, Lincoln University, Canterbury, New Zealand.
}

protein from the degradation of feed constituents account for the majority of nutrients utilized by the host animal (Sutton, 1985). Moreover, the relative concentrations of the individual VFA, mainly acetate, propionate, and butyrate, are important determinants of energy utilization by ruminants because acetate and butyrate are lipogenic nutrients whereas propionate is primarily used as a precursor for glucose. Consequently, both the total amounts as well as the proportions of fermentation end products are important in determining the amount as well as the composition of the milk produced (Sutton, 1985; Thomas and Martin, 1988). Much work has therefore been done on predicting the rumen fermentation pattern. Mechanistic models have been popular for this purpose (Baldwin et al., 1987; Dijkstra et al., 1992), but accuracy of prediction of molar proportions of rumen VFA is low (Bannink et al., 1997). In another approach, Friggens et al. (1998) derived empirical relations between the rumen fermentation pattern and dietary chemical composition in sheep. These equations have not yet been challenged by an independent data set and their accuracy to predict rumen VFA proportions in dairy cattle is uncertain. Alternatively, the gas production test was used to predict molar proportions of VFA in vivo (Brown et al., 2002; Rymer and Givens, 2002) but large differences were observed between the in vivo and in vitro rumen fermentation patterns. Consequently, there is a need for further development of methodology to predict the rumen fermentation pattern. In view of the growing aversion to the use of surgically prepared animals, the development of noninvasive methods providing insight in the rumen fermentation pattern would be of great value, permitting their use in practical dairy cattle feeding and improving research animal welfare. The easy collection of milk explains the increased interest in the analysis of its components as a diagnostic tool for cow health and nutrition (Mottram, 1997; Vlaeminck et al., 2005). In this respect, milk odd- and branched-chain fatty acids could be interesting parameters because 
they mainly originate from bacteria leaving the rumen and recent in vitro work showed the possibility of predicting rumen VFA proportions based on rumen concentrations of these fatty acids (Vlaeminck et al., 2004).

The objective of this work was to evaluate the potential of odd- and branched-chain fatty acids in milk to predict rumen proportions of VFA. First, we investigated the relationship between concentrations of oddand branched-chain fatty acids in milk and rumen proportions of VFA, using data from 10 feeding experiments with rumen-cannulated dairy cows. Second, we validated the developed equations using independent data of experiments reported in literature.

\section{MATERIALS AND METHODS}

\section{Data Set Description}

The current study combined data from 10 experiments, resulting in a data set of 148 individual observations.

Experiment $1(n=24)$. Experimental design and diets are as described by Dewhurst et al. (2003). Briefly, the experiment was according to a 4-period incomplete changeover design, in which 6 cows in the beginning of the lactation were used to test 6 dietary treatments. Each experimental period lasted for $3 \mathrm{wk}$, of which the first 2 wk were for adaptation. Each cow was offered 4 different diets. Cows received $8 \mathrm{~kg} / \mathrm{d}$ of a dairy concentrate (Dewhurst et al., 2003), in 3 portions: $3 \mathrm{~kg}$ at each milking $(0730$ and $1600 \mathrm{~h})$ and $2 \mathrm{~kg}$ at $1200 \mathrm{~h}$. Cows had ad libitum access to 1 of 6 silages: grass, red clover, white clover, alfalfa, and 50/50 (DM basis) mixtures of grass and red clover and grass and white clover. Each forage treatment comprised a proportional mixture of all cuts taken in the year. Fresh forage was distributed daily at $0900 \mathrm{~h}$. Samples of rumen fluid were taken using automated equipment at 2-h intervals during 1 d (12 samples/cow), acidified, and analyzed for VFA (Dewhurst et al., 2003). Milk samples were taken from 4 consecutive milkings and stored frozen.

Experiment $2(\boldsymbol{n}=16)$. This experiment was a $4 \times$ 4 Latin square. Four dairy cows $(90 \pm 34$ DIM at the beginning of the experiment) were offered diets varying in forage-to-concentrate ratio. Dietary treatments were based on ad libitum access to ryegrass silage and a dairy concentrate (Moorby et al., 2006; Vlaeminck et al., $2006 \mathrm{~b}$ ) with forage:concentrate ratios of $80: 20$, 65:35, 50:50, 35:65 on a DM basis (Moorby et al., 2006; Vlaeminck et al., 2006b). Each experimental period lasted for 4 wk of which the first 2 wk were for adaptation. Fresh forage was distributed daily at $0900 \mathrm{~h}$ whereas concentrates were distributed twice daily in equal portions at milking (0800 and 1600 h; Moorby et al., 2006; Vlaeminck et al., 2006b). Samples of rumen fluid were taken using automated equipment at 2-h intervals during $1 \mathrm{~d}$ (12 samples/cow), acidified, and analyzed for VFA (Dewhurst et al., 2003). Milk samples were taken from 4 consecutive milkings and stored frozen.

Experiment $3(\boldsymbol{n}=16)$. Experimental procedures were described previously (Hindle et al., 2005). Each experimental period lasted for 4 wk of which the first 2 wk were for adaptation. Four multicannulated dairy cows ( $80 \pm 18$ DIM at the beginning of the experiment) received either a control diet, consisting of grass silage ( $43 \%$ of DM), ensiled sugar beet pulp ( $11 \%$ of DM), and a concentrate mixture with $70 \%$ dried sugar beet pulp. Dried sugar beet pulp of the concentrate was replaced either by native potato starch, cornmeal, or wheat meal in each of the 3 experimental diets. Diets were distributed twice daily in equal portions as a TMR at 0600 and $1700 \mathrm{~h}$. Rumen fluid was sampled at 4-h intervals during one 24-h period. After each sampling, samples were acidified and stored at $-20^{\circ} \mathrm{C}$ until analysis of VFA (Hindle et al., 2005). Milk samples were taken from 8 consecutive milkings and stored frozen.

Experiment $4(n=16)$. Experimental procedures were described in detail previously (Bruinenberg et al., 2004). Briefly, 4 rumen-cannulated multiparous Holstein cows ( $249 \pm 76$ DIM at the beginning of the experiment) were assigned to a $4 \times 4$ Latin square experiment. Each experimental period lasted for $3 \mathrm{wk}$, of which the first 2 wk were for adaptation. Forages differed between the 4 dietary treatments and consisted of different combinations of 3 grassland silages (Bruinenberg et al., 2004). At 0600 and $1600 \mathrm{~h}$, cows received 40 and 60\% of the daily DM offered, respectively. Over one 24-h period, samples from rumen fluid were taken at 1600 , $1800,2000,2200,2400,0300,0600,0800,1000$, and $1300 \mathrm{~h}$, and analyzed for VFA (Bruinenberg et al., 2004). Milk samples were taken from 4 consecutive milkings and stored frozen.

Experiments 5 and $6(n=50)$. These two experiments were both $5 \times 5$ Latin squares. Five dairy cows in early lactation ( $45 \pm 14$ DIM at the beginning of the experiment; experiment 5) and late lactation (236 \pm 14 DIM at the beginning of the experiment; experiment 6) were offered diets varying in source of forage and concentrate (55/45, DM basis). Dietary treatments were based on ad libitum access to 1 of the 5 TMR: 1) a mixture (50/50, DM basis) of ryegrass silage (CP: $16.6 \%$ of DM, sugar: $3.6 \%$ of DM, NDF: $50.9 \%$ of DM) and corn silage (CP: $7.5 \%$ of DM, sugar: $0.6 \%$ of DM, starch: $31.4 \%$ of DM, NDF: $40.0 \%$ of DM) as forage and a mixture (50/50, DM basis) of 2 concentrates either rich in structural (CP: $19.4 \%$ of DM, sugar: $10.8 \%$ of DM, starch: $1.4 \%$ of DM, NDF: $32.0 \%$ of DM) or in nonstructural carbohydrates (CP: $19.6 \%$ of DM, sugar: $10.5 \%$ of DM, starch: $30.3 \%$ of DM, NDF: $14.6 \%$ of DM); 2) rye- 
grass silage as forage and the concentrate mixture (50/ $50, \mathrm{DM}$ basis) as in diet $1 ; 3$ ) corn silage as forage and the concentrate mixture (50/50, DM basis) as in diet 1 ; 4) a mixture (50/50, DM basis) of ryegrass silage and corn silage as forage and a concentrate rich in structural carbohydrates; 5) a mixture (50/50, DM basis) of ryegrass silage and corn silage as forage and a concentrate rich in nonstructural carbohydrates. Each experimental period lasted for $3 \mathrm{wk}$, of which the first $2 \mathrm{wk}$ were for adaptation. Samples of rumen fluid were taken frequently during one 12-h interval (at least 15 samples/ cow) based on the cow's ingestion pattern, acidified, and analyzed for VFA (Chilibroste et al., 1998). Milk samples were taken from 4 consecutive milkings and stored frozen.

Experiments 7 and $8(n=18)$. These 2 experiments were both $3 \times 3$ Latin squares. Three dairy cows (294 $\pm 148 \mathrm{DIM}$ at the beginning of the experiment) were offered diets with corn and grass silage as forage with a standard dairy concentrate. Corn silage was taken from 2 different varieties varying in starch content. Dietary treatments were based on ad libitum access of forage and $5.1 \mathrm{~kg} / \mathrm{d}$ of the standard dairy concentrate. Each experimental period lasted for $13 \mathrm{~d}$, of which the first $10 \mathrm{~d}$ were for adaptation. Samples of rumen fluid were taken before the morning feeding and 1, 2, 3, 5, and $8 \mathrm{~h}$ after the morning feeding during the last 3 consecutive days. Before VFA analysis (De Boever et al., 2005), rumen samples from the $3 \mathrm{~d}$ were pooled according to their sampling time (6 samples per animal and per treatment). Milk samples were taken from 4 consecutive milkings, pooled and stored frozen.

Experiments 9 and $10(n=8)$. These 2 experiments were both $2 \times 2$ Latin squares. Two dairy cows $(278 \pm$ 108 DIM at the beginning of the experiment) were offered diets with corn and grass silage as forage with a standard dairy concentrate. Corn silage was from 2 different varieties, inducing variation in rumen bypass starch content. Dietary treatments were based on ad libitum access of the forage and $5.1 \mathrm{~kg} / \mathrm{d}$ of a standard dairy concentrate. Each experimental period lasted for $13 \mathrm{~d}$ of which the first $10 \mathrm{~d}$ were for adaptation. Samples of rumen fluid were taken before the morning feeding and $1,2,3,5$, and $8 \mathrm{~h}$ after the morning feeding during 3 consecutive days. Before VFA analysis (De Boever et al., 2005), rumen samples of the $3 \mathrm{~d}$ were pooled according to their sampling time (6 samples per animal and per treatment). Milk samples were taken from 4 consecutive milkings, pooled, and stored frozen.

\section{Milk Fatty Acid Analysis}

In all the experiments, milk samples were extracted, methylated, and analyzed by GLC as described by Vlae- minck et al. (2005). Briefly, in the first step, samples were extracted with ammonium hydroxide solution, ethanol, diethyl ether, and petroleum ether. In the second extraction step, ethanol, diethyl ether, and petroleum ether were used, and in the final extraction step, the solvents used were diethyl ether and petroleum ether. Extracts from the 3 consecutive steps were combined, evaporated, methylated, and analyzed separately for short-chain fatty acids (C4:0 to $\mathrm{C} 10: 0)$ and medium- and long-chain fatty acids (C12:0 to C24:0). Standard curves were used to determine the response factors for milk short-chain fatty acids, taking into account tridecanoic acid (Sigma, Bornem, Belgium) as the internal standard, whereas the other fatty acids were quantified with nonadecanoic acid as the internal standard (Sigma). Methylation and analysis by GLC were described previously (Vlaeminck et al., 2005).

\section{Calculations}

Mean 24-h molar proportions of VFA were calculated from the results of the individually analyzed samples, taken in relation to the cow's feeding pattern as described before for the different experiments. Because time intervals between samplings were not the same in each experiment, hourly values were calculated by linear interpolation of values for the next and previous sampling. From these 24 values, mean molar proportions of acetate, propionate, and butyrate $[\mathrm{mmol} / \mathrm{mol}$ (acetate + propionate + butyrate)] for each sampling day were calculated.

Milk odd- and branched-chain fatty acids were expressed as g/100 $\mathrm{g}$ of fatty acids and individual oddand branched-chain fatty acids were used to construct the model. However, because cis-9 C17:1 is a desaturation product of C17:0 in the mammary gland (Fievez et al., 2003a), the sum of C17:0 and cis-9 C17:1 was used.

\section{Independent Data Set to Evaluate Accuracy of Prediction}

Qualitative Evaluation. Because of the limited data available in literature reporting both rumen fermentation pattern and milk odd- and branched-chain fatty acids, we first performed a qualitative evaluation of the regression equations: using milk odd- and branched-chain fatty acids, reported by Kraft et al. (2003), Loor et al. (2005a,c), and Van Nespen et al. (2005), we calculated the associated VFA proportions from the regression equations based on milk odd- and branched-chain fatty acids developed in the current study. Because the VFA proportions were not measured in these studies (Kraft et al., 2003; Loor et al., 2005a,c; Van Nespen et al., 2005), the qualitative evaluation 
assessed the ability of the equations to predict wellknown shifts in the fermentation pattern induced by varying roughage proportions (Kraft et al., 2003) or supplementation of fish (Loor et al., 2005a,c) or vegetable oils (Loor et al., 2005a) and rumen-degradable starch (Van Nespen et al., 2005).

Quantitative Evaluation. Data from the experiments described by Shingfield et al. $(2003,2005)$ and Loor et al. (2005b) were used to evaluate the accuracy of equations developed to predict rumen proportions of VFA based on milk odd- and branched-chain fatty acids. To our knowledge, these are the only published articles with information on both rumen fermentation pattern and milk odd- and branched-chain fatty acids in the same experiments, albeit in separate papers. The resulting test data set consisted of 14 observations.

\section{Statistics}

All statistical analyses were performed using SPSS 12.0 (SPSS software for Windows, release 12.0, SPSS, Inc., Chicago, IL).

Linear Regression Analyses. Regression analyses were performed using the linear mixed models procedure with the discrete effect of study included as a random variable (St-Pierre, 2001). All individual oddand branched-chain fatty acids were introduced in the model and equations were developed by running multiple iterations and removing the least significant effect at each iteration. Variables were kept in the model when $P$-values were below 0.10 . Regression equations were evaluated based on the standard error and coefficients of variation and by regressing residuals on the predicted values. Predicted values were centered by subtracting the mean of all predicted values from each prediction (St-Pierre, 2003). Mean biases were assessed using the intercepts of the regression equations, and the slopes of the regression equations were used to determine the presence of linear biases.

Independent Data Sets to Evaluate Accuracy of Prediction. The regression equations developed in this study were validated with independent data sets using the mean square prediction error (MSPE; Bibby and Toutenberg, 1977):

$$
M S P E=\frac{1}{n} \times \sum_{i=1}^{n}\left(y_{i}-\hat{y}_{i}\right)^{2}
$$

where $n$ is the number of observations, and $y_{i}$ and $\hat{y}_{i}$ are the observed and predicted values, respectively. The square root of MSPE is expressed in the same units as the observed values and a comparison of the root MSPE as a percentage of the observed mean provides an indication of the overall error of prediction. The MSPE was further decomposed into 3 components; mean bias, line bias (deviation from the regression slope from one), and the disturbance proportion indicating random deviation, which cannot be accounted for by bias or regression deviation. Further, residuals were regressed on the predicted values as described before.

\section{RESULTS}

\section{Data File Description}

Data were gathered from a wide range of experimental conditions, which is reflected in the wide range of rumen proportions of acetate, propionate, and butyrate (Table 1). Large differences were also observed in the proportions of odd- and branched-chain fatty acids in milk fat (Table 1). Anteiso C15:0 and linear odd-chain fatty acids showed the lowest variation coefficient. Dietary effects on milk odd- and branched-chain fatty acids falls out of the scope of the current paper but are the subject of detailed discussion in a review paper (Vlaeminck et al., 2006a).

\section{Model Development}

The relations between milk odd- and branched-chain fatty acids and rumen fermentation pattern are presented in Table 2. Milk iso C14:0 and iso C15:0 were positively related with rumen proportions of acetate, whereas a negative relation was observed with the linear odd-chain fatty acids (Equation [1] in Table 2). Due to the strong negative relation between rumen proportions of acetate and propionate, independent variables in the predictive model for acetate were also retained in the model to predict rumen proportions of propionate. Iso C14:0 and iso C15:0 were negatively related with molar proportions of propionate, whereas linear oddchain fatty acids and iso C16:0 showed a positive relation (Equation [2] in Table 2). In the predictive model of butyrate, only anteiso $\mathrm{C} 15: 0$ and C15:0 were retained in the equation. These fatty acids were negatively related with rumen proportions of butyrate (Equation [3] in Table 2). All models showed a good predictive capacity as indicated by a reasonably low $\mathrm{SE}$ and variation coefficient (Table 1). In addition, residuals were tested for significant mean and linear biases and, as expected, the biases were not significant. Residual plots for the models are shown in Figure 1.

\section{Model Validation}

Descriptive statistics for the data used to qualitatively and quantitatively validate the regression equations are presented in Table 3. Some studies did not report all variables; therefore, the number of observa- 
Table 1. Summary statistics of experimental data used for model development $(\mathrm{n}=148)$

\begin{tabular}{lcccc}
\hline & Mean & SD & Minimum & Maximum \\
\hline Rumen fermentation pattern & & & & \\
Total VFA (mmol/L) & 107 & 22.5 & 50 & 143 \\
Acetate (mmol/mol) & 659 & 34.6 & 548 & 724 \\
Propionate (mmol/mol) & 209 & 29.4 & 158 & 322 \\
Butyrate (mmol/mol) & 132 & 16.9 & 98 & 184 \\
Milk odd- and branched-chain fatty acids (g/100 g of fatty acids) & & \\
iso C13:0 & 0.024 & 0.006 & 0.007 & 0.045 \\
iso C14:0 & 0.085 & 0.021 & 0.031 & 0.154 \\
iso C15:0 & 0.217 & 0.042 & 0.116 & 0.325 \\
iso C16:0 & 0.190 & 0.043 & 0.119 & 0.362 \\
iso C17:0 & 0.188 & 0.041 & 0.111 & 0.184 \\
anteiso C13:0 & 0.085 & 0.028 & 0.020 & 0.701 \\
anteiso C15:0 & 0.470 & 0.067 & 0.309 & 0.833 \\
anteiso C17:0 & 0.535 & 0.102 & 0.353 & 1.564 \\
C15:0 & 1.088 & 0.164 & 0.700 & 1.133 \\
C17:0 + cis-9 C17:1 & 0.701 & 0.106 & 0.507 & \\
\hline
\end{tabular}

tions across dependent variables was not constant. In general, values of most variables in the data set for model validation (Table 3 ) were within the range of the values used for model development (Table 1). Nevertheless, iso C13:0 was considerably higher in the validation data set. In addition, maximum values of iso $\mathrm{C} 14: 0$ and iso C17:0 were slightly higher compared with the data set used for model development.

Qualitative Evaluation. Acetate, propionate, and butyrate proportions, predicted from average odd- and branched-chain fatty acid concentrations in milk from dairy cows fed diets known to induce variation in the rumen fermentation pattern (Kraft et al., 2003; Loor et al., 2005a,c; Van Nespen et al., 2005) are presented in Table 4. Fish oil increased the predicted rumen proportions of propionate in the experiments of Loor et al. (2005a,c). Diets high in rumen-degradable starch (Van Nespen et al., 2005) decreased predicted acetate and increased propionate proportions. Dairy cows of organic farms compared with conventional farms were higher in predicted acetate and lower in propionate (Kraft et al., 2003).

Quantitative Evaluation. Results of the present validation of the predictive models with an independent data set are presented in Table 5. The root MSPE values obtained with the independent data set ranged from 10.9 to $20.5 \mathrm{mmol} / \mathrm{mol}$ (Table 5 ). The mean predicted values for propionate were close to the mean actual

Table 2. Equations to predict rumen proportions of VFA $(\mathrm{mmol} / \mathrm{mol})$ from milk odd and branched-chain fatty acids $(\mathrm{g} / 100 \mathrm{~g}$ fat $)(\mathrm{n}=148)$

\begin{tabular}{|c|c|c|c|c|c|c|c|c|c|c|}
\hline & \multicolumn{3}{|c|}{ Intercept } & \multicolumn{4}{|c|}{ Independent variable } & $\begin{array}{l}\text { Residual } \\
\text { SE }\end{array}$ & $\mathrm{CV}^{1}$ & $\begin{array}{l}\text { SE of } \\
\text { study }\end{array}$ \\
\hline \multicolumn{11}{|l|}{$\begin{array}{l}\text { Equation [1] to predict ruminal } \\
\text { proportions of acetate (mmol/mol) }\end{array}$} \\
\hline & 666 & 19.4 & $<0.001$ & iso $\mathrm{C} 14: 0$ & 352 & 101.2 & 0.001 & 15.3 & 2.33 & 24.9 \\
\hline & & & & iso $\mathrm{C} 15: 0$ & 133 & 53.4 & 0.014 & & & \\
\hline & & & & C15:0 & -26.5 & 11.4 & 0.022 & & & \\
\hline & 148 & 18.1 & $<0.001$ & iso $\mathrm{C} 14: 0$ & -332 & 112.2 & 0.004 & 14.7 & 7.05 & 18.7 \\
\hline & & & & iso $\mathrm{C} 15: 0$ & -116 & 51.4 & 0.026 & & & \\
\hline & & & & C15:0 & 57.6 & 10.96 & $<0.001$ & & & \\
\hline & & & & iso $\mathrm{C} 16: 0$ & 78.6 & 47.15 & 0.098 & & & \\
\hline & & & & $\mathrm{C} 17: 0+c i s-9 \mathrm{C} 17: 1$ & 51.0 & 17.48 & 0.004 & & & \\
\hline \multicolumn{11}{|l|}{$\begin{array}{l}\text { Equation [3] to predict ruminal } \\
\text { proportions of butyrate }(\mathrm{mmol} / \mathrm{mol})\end{array}$} \\
\hline
\end{tabular}

\footnotetext{
${ }^{1} \mathrm{CV}=$ Coefficient of variation $(\%)$.

${ }^{2} \mathrm{SE}=$ Standard error of the regression coefficient.

${ }^{3} P=P$-value of the regression coefficient.
} 


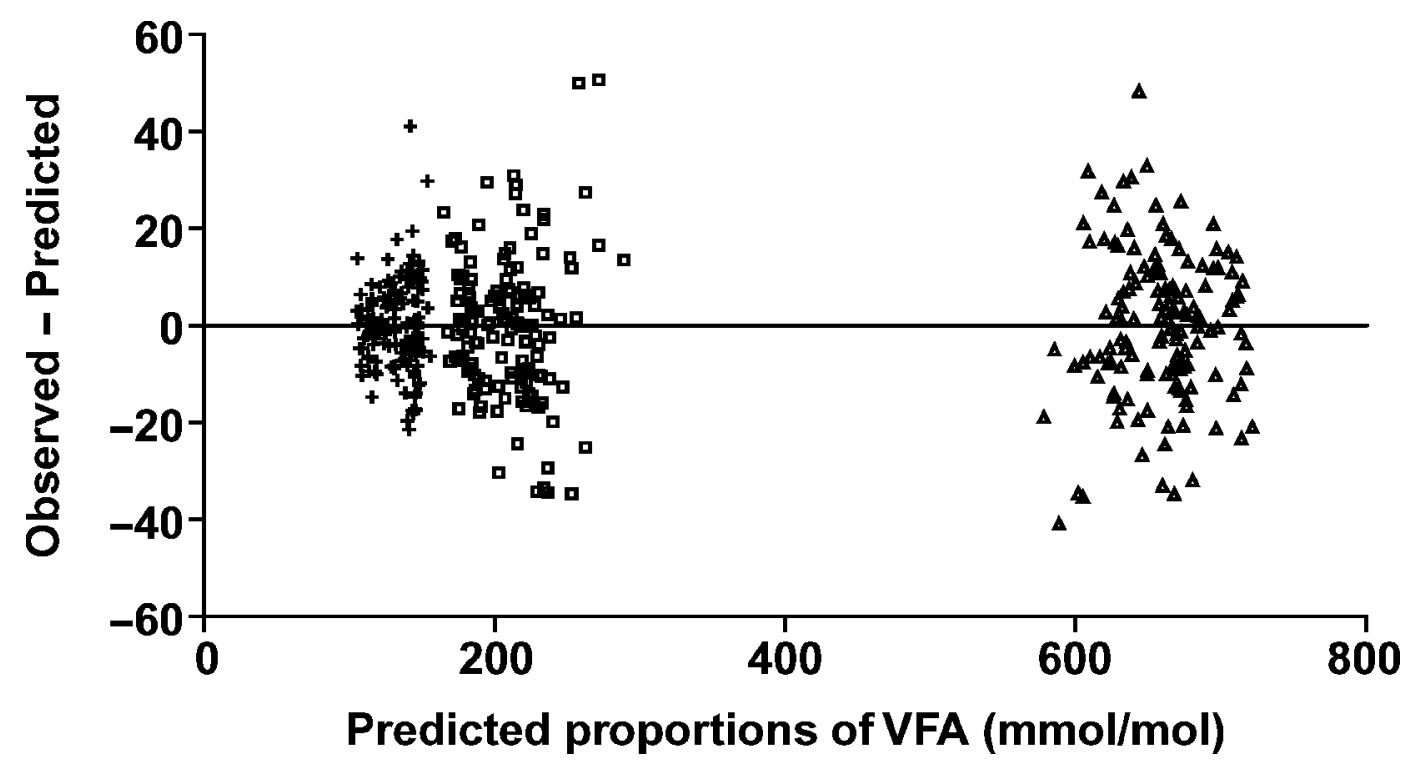

Figure 1. Plot of observed minus predicted molar proportions of acetate $(\triangle)$, propionate $(\square)$ and butyrate $(+)$ vs. predicted molar proportions of acetate, propionate, and butyrate. Predictive models were based on milk odd- and branched-chain fatty acids (g/100 g fat) (Equations [1], [2], and [3] in Table 2) ( $\mathrm{n}=148)$.

data. In contrast, the model for predicting rumen proportions of acetate underpredicted actual values, whereas the opposite was observed for butyrate. Accordingly, a relatively large error derived from the mean bias as a proportion of total MSPE was derived in equations for predicting acetate and butyrate. The prediction of the rumen fermentation pattern produced a relatively small error of line (slope) as a proportion of total MSPE $(<5 \%)$. The root MSPE expressed as a percentage of the observed mean was less than $3 \%$ for predictions of rumen acetate proportions and increased to $9 \%$ for predictions of propionate and butyrate (Table 5). Residual plots are shown in Figure 2. The equation predicting the acetate proportion underpredicted actual acetate proportions by, on average, $14.2 \mathrm{mmol} / \mathrm{mol}$. In none of the equations was line bias significantly different from zero $(P>0.5)$. The highest deviation from the actual values was observed for the linseed oil supplemented

Table 3. Summary statistics of experimental data used for qualitative ${ }^{1}$ and quantitative $^{2}$ model validation

\begin{tabular}{lccccc}
\hline & $\mathrm{n}$ & Mean & SD & Minimum & Maximum \\
\hline Rumen fermentation pattern $^{2}$ & & & & & \\
$\quad$ Total VFA (mmol/l) & 14 & 87 & 13.1 & 72 & 115 \\
Acetate (mmol/mol) & 14 & 684 & 21.2 & 637 & 709 \\
Propionate (mmol/mol) & 14 & 196 & 26.0 & 173 & 263 \\
$\quad$ Butyrate (mmol/mol) & 14 & 120 & 11.1 & 100 & 139 \\
Milk odd and branched-chain fatty acids & & & & & \\
(g/100 g of fatty acids) & & & & & \\
iso C13:0 & 16 & 0.083 & 0.052 & 0.011 & 0.144 \\
iso C14:0 & 27 & 0.107 & 0.040 & 0.038 & 0.179 \\
iso C15:0 & 27 & 0.245 & 0.062 & 0.137 & 0.356 \\
iso C16:0 & 19 & 0.231 & 0.067 & 0.115 & 0.330 \\
iso C17:0 & 18 & 0.278 & 0.184 & 0.143 & 0.840 \\
anteiso C13:0 & 16 & 0.087 & 0.033 & 0.025 & 0.127 \\
anteiso C15:0 & 27 & 0.524 & 0.128 & 0.299 & 0.760 \\
anteiso C17:0 & 16 & 0.466 & 0.098 & 0.354 & 0.637 \\
C15:0 & 27 & 1.138 & 0.174 & 0.830 & 1.461 \\
C17:0 + cis-9 C17:1 & 27 & 0.844 & 0.172 & 0.598 & 1.231 \\
\hline
\end{tabular}

${ }^{1}$ Kraft et al. (2003); Loor et al. (2005a,c); Van Nespen et al. (2005). Of these experiments, no information on the rumen fermentation pattern is available.

${ }^{2}$ Shingfield et al., 2003, 2005; Loor et al., 2005b. Rumen fermentation pattern of experiments described by Loor et al. (2005b) and Shingfield et al. (2005) are reported by Ueda et al. (2003) and Shingfield et al. (2001), respectively. 
Table 4. Predicted rumen proportions of VFA (mmol/mol) using Equations [1], [2], and [3] developed in the present study (Table 2) and observed milk odd and branched-chain fatty acid concentrations in published studies

\begin{tabular}{lllll}
\hline Reference & Diet & Acetate [1] & Propionate [2] & Butyrate [3] \\
\hline Kraft et al. (2003) & German indoor & 666 & 217 & 130 \\
Loor et al. (2005a) & German organic & 686 & 199 & 126 \\
& Fish oil & 661 & 226 & 114 \\
& Linseed oil & 656 & 203 & 136 \\
Loor et al. (2005c) & Sunflower oil & 664 & 202 & 133 \\
& Control & 678 & 206 & 124 \\
Van Nespen et al. (2005) & Ruminal infusion of fish oil & 654 & 223 & 119 \\
& Control & 649 & 205 & 139 \\
& High rumen-degradable starch & 628 & 232 & 133 \\
\hline
\end{tabular}

diets reported by Loor et al. (2005b). With these diets, propionate was underpredicted by $36 \mathrm{mmol} / \mathrm{mol}$, whereas butyrate was overpredicted by $23 \mathrm{mmol} / \mathrm{mol}$.

\section{DISCUSSION}

Because in vivo quantification of VFA production is difficult and expensive, only VFA concentrations in rumen fluid are measured routinely in rumen digestion trials. This implies the assumption that VFA proportions in rumen fluid represent proportions in which they are produced. However, molar proportions of VFA in rumen fluid may be an unreliable estimate of the relative proportion of production rates where the fractional absorption rates of individual VFA differ (Dijkstra, 1994). Nevertheless, in a recent study, Sutton et al. (2003) found a close relation of the molar proportions of net production to molar proportions of concentrations, particularly for acetate and propionate. This implies that the readily measured and widely published values for VFA proportions in the rumen provide a close estimate of the molar proportions of acetic and propionic acid available for absorption (Sutton et al., 2003). Accordingly, molar proportions of rumen VFA provides information that is of nutritive value to the animal.
Hence, efforts to accurately estimate these proportions, based on noninvasive methodology, seem justified.

\section{Model Development}

The regression equation showed that milk iso C14:0 and iso C15:0 are positively related to rumen proportions of acetate. In a literature review, Vlaeminck et al. (2006a) described a positive relation between dietary $\mathrm{NDF}$ content and milk iso C14:0 and iso C15:0. In addition, studies reporting odd- and branched-chain fatty acids of mixed rumen bacteria show an increase in these fatty acids when forage:concentrate ratio increases (Bas et al., 2003; Vlaeminck et al., 2006b). Higher dietary $\mathrm{NDF}$ and an increase in forage:concentrate ratio generally increases the importance of cellulolytic bacteria (Dehority and Orpin, 1988; Weimer et al., 1999). Fatty acid analysis of pure strains of rumen bacteria have shown that some major cellulolytic bacteria are enriched in iso $\mathrm{C} 14: 0$ and iso C15:0 (see, for example, Ifkovitz and Ragheb 1968; Minato et al., 1988). Because the latter bacteria are mainly acetate producers, it is not surprising that the coefficient of iso C14:0 and iso $\mathrm{C} 15: 0$ is positive in the acetate-predicting equation. Linear odd-chain fatty acids were positively related

Table 5. Validation of prediction equations [1], [2], and [3] developed in the present study (Table 2) using the mean square prediction error (MSPE) and the rumen fermentation pattern ${ }^{1}$ and milk odd and branchedchain fatty acids published in Shingfield et al. $(2003,2005)$ and Loor et al. (2005b) $(\mathrm{n}=14)$

\begin{tabular}{llll}
\hline & Acetate [1] & Propionate [2] & Butyrate [3] \\
\hline Observed $(\mathrm{mmol} / \mathrm{mol})$ & $684 \pm 21.2$ & $196 \pm 26.0$ & $120 \pm 11.1$ \\
Predicted $(\mathrm{mmol} / \mathrm{mol})$ & $670 \pm 16.5$ & $199 \pm 22.0$ & $124 \pm 5.5$ \\
Root MSPE $(\mathrm{mmol} / \mathrm{mol})$ & 20.5 & 17.7 & 10.7 \\
Root MSPE $(\%)^{2}$ & 3.00 & 9.01 & 8.93 \\
Proportion $(\%)$ of MSPE due to: & & & \\
Mean bias & 48.0 & 3.0 & 17.5 \\
Line & 0.7 & 2.7 & 0.6 \\
Random & 51.3 & 94.3 & 81.9 \\
\hline
\end{tabular}

${ }^{1}$ Rumen fermentation pattern of experiments described by Loor et al. (2005b) and Shingfield et al. (2005) are reported by Ueda et al. (2003) and Shingfield et al. (2001), respectively.

${ }^{2}$ Root MSPE expressed as a percentage of the observed mean. 

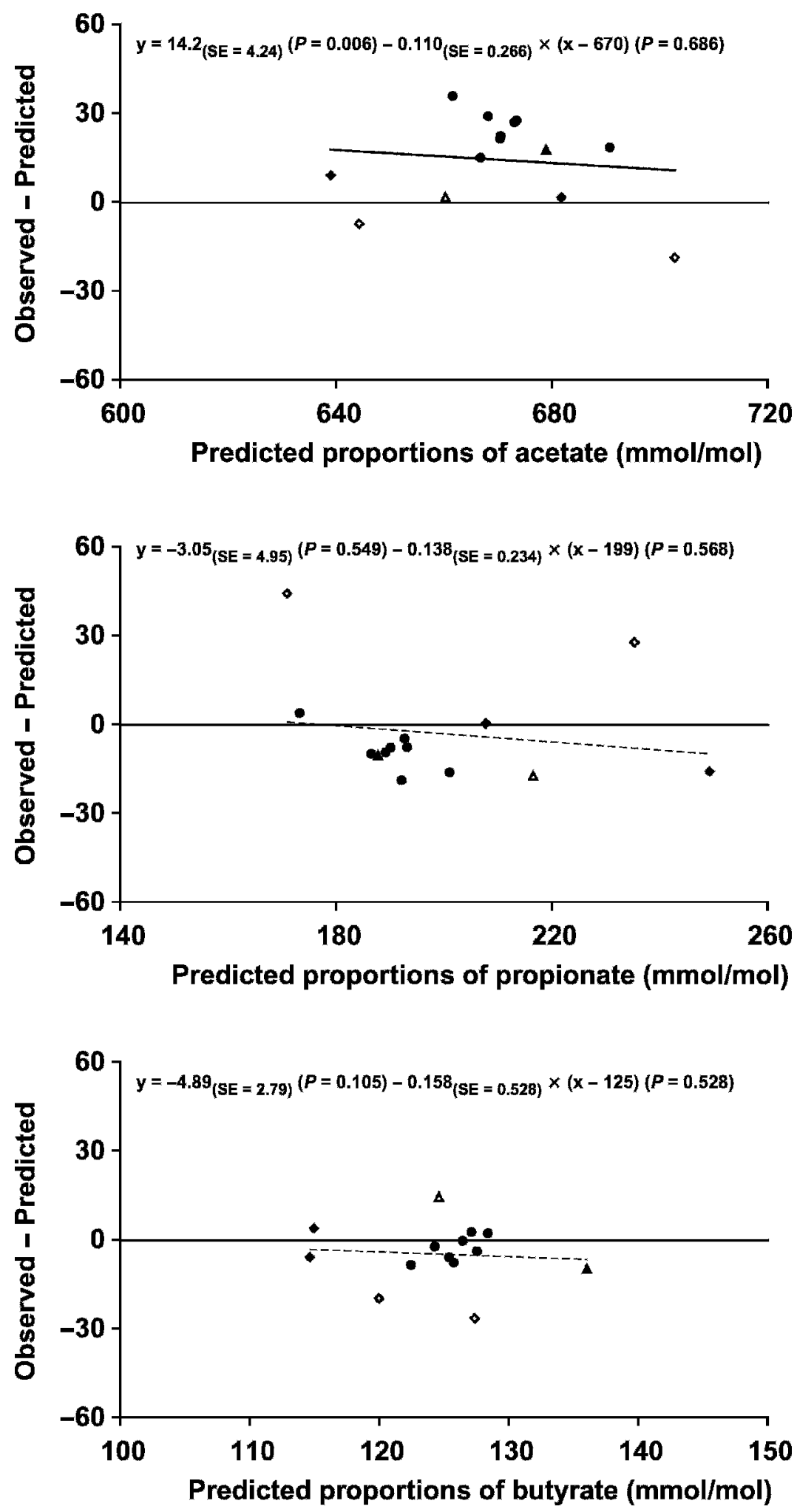

Figure 2. Plot of observed minus predicted molar proportions ( $\mathrm{mmol} / \mathrm{mol})$ of acetate $(\mathrm{A})$, propionate (B), and butyrate (C) vs. predicted molar proportions of acetate, propionate, and butyrate for validation of Equations [1], [2], and [3] (Table 2). Data used for validation were from Shingfield et al. (2003; triangles), Loor et al. (2005b; diamonds) and Shingfield et al. (2005; circles). Full symbols represent dietary treatments not supplemented with fat; open symbols represent diets supplemented with linseed oil (Loor et al., 2005b) or fish oil (Shingfield et al., 2003). 
with rumen proportions of propionate. During in vitro incubations, Vlaeminck et al. (2004) also found a positive relation between C15:0 and rumen proportions of propionate. This suggests that rumen conditions inducing high propionate production are favorable for bacteria synthesizing linear odd-chain fatty acids. Indeed, amylolytic bacteria (e.g., Ruminobacter amylophilus, Succinivibrio dextrinosolvens) show low levels of branched-chain fatty acids and are relatively enriched in linear odd-chain fatty acids (see, for example, Ifkovitz and Ragheb 1968; Minato et al., 1988). In addition, high rumen proportions of propionate might have stimulated 1) incorporation of propionyl-CoA in bacterial fatty acids (Fulco, 1983), and 2) de novo synthesis of linear odd-chain fatty acids from propionyl-CoA in the mammary gland (Vlaeminck et al., 2006a). These finding might also partially explain the positive relation between linear odd-chain fatty acids and rumen proportions of propionate.

Friggens et al. (1998) derived empirical equations based on observations in sheep to quantify the effect of dietary chemical components on rumen fermentation pattern. In their model development, a residual standard deviation of $11.4,9.9$, and $6.6 \mathrm{mmol} / \mathrm{mol}$ was reported for acetate, propionate, and butyrate, respectively. Recently, Bannink et al. (2006) estimated stoichiometric coefficients for VFA production from fermented substrates using literature data from experiments with dairy cows. The root mean square error values in their study were $32.6,29.4$, and $14.3 \mathrm{mmol} /$ $\mathrm{mol}$ for acetate, propionate, and butyrate, respectively. Results from the present study show intermediate $\mathrm{SE}$ values $(15.3,14.7$, and $9.2 \mathrm{mmol} / \mathrm{mol}$ for acetate, propionate, and butyrate, respectively). This suggests that prediction of rumen fermentation pattern based on milk odd- and branched-chain fatty acids might be a promising alternative to equations based on dietary characteristics.

\section{Model Validation}

Although the relatively low SE supports the validity of the fitted regression model (Neter et al., 1996), comparison of MSPE values obtained with an independent data set is the best way to evaluate the accuracy of different equations. Due to the limited data available in the literature reporting both rumen fermentation pattern and milk odd- and branched-chain fatty acids, we first did a qualitative evaluation of the regression equations using milk odd- and branched-chain fatty acids reported by Kraft et al. (2003), Loor et al. (2005a,c), and Van Nespen et al. (2005). During this evaluation, prediction equations were solely evaluated on well-documented and expected changes in the rumen fermentation pattern because the latter was not measured in these studies.

Qualitative Evaluation. Ruminal infusion of fish oil (Loor et al., 2005c) resulted in a predicted decrease of acetate whereas propionate increased. This shift in the rumen fermentation pattern toward an increased propionate production when supplementing fish oil is well documented (see Doreau and Chilliard, 1997; Fievez et al., 2003b). Similarly, diets high in rumen-degradable starch (Van Nespen et al., 2005) are known to decrease acetate and increase propionate proportions, as confirmed by the current predictions. Kraft et al. (2003) reported an increase in iso C14:0 and iso C15:0 in milk from cows of organic farms compared with conventional farms, resulting in a higher predicted acetate proportion and lower propionate. This was probably a reflection of the higher roughage proportion of the diets fed on organic farms (Kraft et al., 2003). In conclusion, results from this first qualitative evaluation show that predictions of rumen proportions of VFA based on milk odd- and branched-chain fatty acids were in line with the expected changes.

Quantitative Evaluation. Validation of the prediction equations with the independent data set suggests that milk odd- and branched-chain fatty acids show potential to predict the rumen fermentation pattern. Indeed, the root MSPE as a percentage of the observed mean was less than $10 \%$. In an evaluation of existing mechanistic models, Bannink et al. (1997) found that current models predict the molar proportions of individual VFA in the rumen of cattle inaccurately with a root MSPE ranging from 8.9 to 50.0 for molar proportions of acetate, 45.5 to 97.0 for propionate, and 15.0 to 53.2 for butyrate. Only the mechanistic model of Baldwin et al. (1987) showed better root MSPE values for molar proportions of acetate compared with the proposed predictions based on milk odd- and branched-chain fatty acids. Using newly estimated values of stoichiometric coefficients, Bannink et al. (2000) found a root MSPE of 24.1, 21.0, and 12.0 for molar proportions of acetate, propionate, and butyrate, respectively. Similar values were found by Nagorcka et al. (2000) using different stoichiometric coefficients for the 3 microbial groups currently represented in mechanistic models (root MSPE of 18.2, 31.3, and 21.0 for molar proportions of acetate, propionate, and butyrate, respectively). These values were slightly higher than the values observed using milk odd- and branched-chain fatty acids. However, an integrated comparison between the different models (mechanistic models vs. models based on milk odd- and branched-chain fatty acids) is hindered because of the different sets of data used. In addition, validations based on data from a few trials only may result in particularly favorable or unfavorable valida- 
tions if trials near or far from the average trial used to define the model are used, respectively (Oldick et al., 1999).

The partition of MSPE into 3 components (mean bias, line bias, and random variation) suggests that random variation is the major cause of inaccuracy in the prediction of rumen VFA. A relatively high proportion of MSPE ( $>10 \%$ ) was due to mean bias in the prediction of acetate and butyrate. The large amount of carbon exchange between acetate and butyrate (Sutton et al., 2003) might explain the underprediction of acetate and concomitant overprediction of butyrate. The biological consequence of this inaccurate prediction of the mean molar proportions of acetate and butyrate seems limited, because both are lipogenic VFA. Indeed, when molar proportions of lipogenic VFA (i.e., sum of acetate and butyrate) or the lipogenic:glucogenic ratio was calculated from the predictions of individual VFA, the root MSPE expressed as a percentage of the observed mean was 2.8 and $11.2 \%$ without significant mean and linear bias, despite the significant mean bias for predictions of acetate and butyrate.

The large deviation from the actual values observed for the linseed oil supplemented diets (Loor et al., $2005 \mathrm{~b}$ ) might indicate that the developed equations are not adequate when dairy cows are fed lipid supplements. Indeed, in none of the dietary treatments used for model development were lipids supplemented. The average fatty acid content of the diets used for model development was $22.4 \pm 5.4 \mathrm{~g} / \mathrm{kg}$ of DM (11.8 to $34.8 \mathrm{~g} /$ $\mathrm{kg}$ of DM), a value far below the fatty acid content of the linseed supplemented diets ( $49 \mathrm{~g} / \mathrm{kg}$ of DM; Loor et al., 2005b). The higher dietary fatty acid content might have reduced de novo synthesis of bacterial fatty acids or have resulted in a dilution with greater concentrations of even-chain fatty acids in milk. Hence, to improve prediction accuracy, dietary fatty acid content might have to be included in the regression equations. Furthermore, additional studies are needed to identify the effects of other factors, such as lactation stage, parity, and contribution of odd- and branched-chain fatty acids from body fat to milk odd- and branched-chain fatty acids, particularly during periods of negative energy balance.

\section{CONCLUSIONS}

Milk odd- and branched-chain fatty acids showed a strong relation with the molar proportions of individual VFA in the rumen. Hence, measurement of milk oddand branched-chain fatty acids could give insight in the rumen fermentation pattern in noncannulated dairy cows. This noninvasive method would be advantageous in practical dairy cattle feeding as well as for research purposes. However, to fully exploit the potential of these milk parameters, more experiments are needed to evaluate the effect of other factors such as dietary lipid supplementation.

\section{ACKNOWLEDGMENTS}

The Ph.D. research of Bruno Vlaeminck is supported by the Institute for the Promotion of Innovation through Science and Technology in Flanders.

\section{REFERENCES}

Baldwin, R. L., J. H. M. Thornley, and D. E. Beever. 1987. Metabolism of the lactating cow. II. Digestive elements of a mechanistic model. J. Dairy Res. 54:107-131.

Bannink, A., H. De Visser, and A. M. van Vuuren. 1997. Comparison and evaluation of mechanistic rumen models. Br. J. Nutr. 78:563-581.

Bannink, A., J. Kogut, J. Dijkstra, J. France, E. Kebreab, A. M. Van Vuuren, and S. Tamminga. 2006. Estimation of the stoichiometry of volatile fatty acid production in the rumen of lactating cows. J. Theor. Biol. 1:36-51.

Bannink, A., J. Kogut, J. Dijkstra, J. France, S. Tamminga, and A. M. van Vuuren. 2000. Modelling production and portal appearance of volatile fatty acids in dairy cows. Pages 87-102 in Modelling nutrient utilization in farm animals. J. P. McNamara, J. France, and D. E. Beever, ed. CAB International, Wallingford, UK.

Bas, P., H. Archimede, A. Rozeau, and D. Sauvant. 2003. Fatty acid composition of mixed-rumen bacteria: Effect of concentration and type of forage. J. Dairy Sci. 86:2940-2948.

Bibby, J., and H. Toutenberg. 1977. Prediction and improvement estimation in linear models. John Wiley \& Sons, London, UK.

Brown, V. E., C. Rymer, R. E. Agnew, and D. I. Givens. 2002. Relationship between in vitro gas production profiles of forages and in vivo rumen fermentation patterns in beef steers fed those forages. Anim. Feed Sci. Technol. 98:13-24.

Bruinenberg, M. H., H. Valk, P. C. Struik, and A. M. van Vuuren. 2004. Fermentation and degradation in the rumen of dairy cows fed on diets consisting of silage from an intensively managed sward and silages from semi-natural grasslands. J. Agric. Sci. 142:79-88.

Chilibroste, P., S. Tamminga, J. Van Bruchem, and P. L. Van der Togt. 1998. Effect of allowed grazing time, inert rumen bulk and length of starvation before grazing, on the weight, composition and rumen fermentative end products of the rumen contents of lactating dairy cows. Grass Forage Sci. 53:146-156.

De Boever, J. L., J. M. Aerts, J. M. Vanacker, and D. L. De Brabander. 2005. Evaluation of the nutritive value of maize silages using a gas production technique. Anim. Feed Sci. Technol. 123-124:255-265.

Dehority, B. A., and C. G. Orpin. 1988. Development of, and natural fluctuations in, rumen microbial populations. Pages 151-183 in The rumen microbial ecosystem. P. N. Hobson, ed. Elsevier Science Publishers, London, UK.

Dewhurst, R. J., W. J. Fisher, J. K. S. Tweed, and R. J. Wilkins. 2003. Comparison of grass and legume silages for milk production. 1. Production responses with different levels of concentrate. J. Dairy Sci. 86:2598-2611.

Dijkstra, J. 1994. Production and absorption of volatile fatty acids in the rumen. Livest. Prod. Sci. 39:61-69.

Dijkstra, J., H. D. Neal, D. E. Beever, and J. France. 1992. Simulation of nutrient digestion, absorption, and outflow in the rumen: Model description. J. Nutr. 122:2239-2256.

Doreau, M., and Y. Chilliard. 1997. Effects of ruminal or postruminal fish oil supplementation on intake and digestion in dairy cows. Reprod. Nutr. Dev. 37:113-124.

Fievez, V., F. Dohme, M. Danneels, K. Raes, and D. Demeyer. 2003b. Fish oils as potent rumen methane inhibitors and associated 
effects on rumen fermentation in vitro and in vivo. Anim. Feed Sci. Technol. 104:41-58.

Fievez, V., B. Vlaeminck, M. S. Dhanoa, and R. J. Dewhurst. 2003a. Use of principal component analysis to investigate the origin of heptadecenoic and conjugated linoleic acids in milk. J. Dairy Sci. 86:4047-4053.

Friggens, N. C., J. D. Oldham, R. J. Dewhurst, and G. Horgan. 1998. Proportions of volatile fatty acids in relation to the chemical composition of feeds based on grass silage. J. Dairy Sci. 81:1331-1344.

Fulco, A. J. 1983. Fatty acid metabolism in bacteria. Prog. Lipid Res. 22:133-160.

Hindle, V. A., A. M. van Vuuren, A. Klop, and J. W. Cone. 2005. An evaluation of in vitro estimates for the amounts of rumen bypass starch and whole tract starch digestibility in dairy cattle. J. Anim. Physiol. Anim. Nutr. (Berl.) 89:158-165.

Ifkovitz, R. W., and H. S. Ragheb. 1968. Cellular fatty acid composition and identification of rumen bacteria. Appl. Microbiol. 16:1406-1413.

Kraft, J., M. Collomb, P. Möckel, R. Sieber, and G. Jahreis. 2003. Differences in CLA isomer distribution of cow's milk lipids. Lipids 38:657-664.

Loor, J. J., M. Doreau, J. M. Chardigny, A. Ollier, J. L. Sebedio, and Y. Chilliard. 2005c. Effects of ruminal or duodenal supply of fish oil on milk fat secretion and profiles of trans-fatty acids and conjugated linoleic acid isomers in dairy cows fed maize silage. Anim. Feed Sci. Technol. 119:227-246.

Loor, J. J., A. Ferlay, A. Ollier, M. Doreau, and Y. Chilliard. 2005b. Relationship among trans and conjugated fatty acids and bovine milk fat yield due to dietary concentrate and linseed oil. J. Dairy Sci. 88:726-740.

Loor, J. J., A. Ferlay, A. Ollier, K. Ueda, M. Doreau, and Y. Chilliard. 2005a. High-concentrate diets and polyunsaturated oils alter trans and conjugated isomers in bovine rumen, blood, and milk. J. Dairy Sci. 88:3986-3999.

Minato, H., S. Ishibashi, and T. Hamaoka. 1988. Cellular fatty acid and sugar composition of representative strains of rumen bacteria. J. Gen. Appl. Microbiol. 34:303-319.

Moorby, J. M., R. J. Dewhurst, R. T. Evans, and J. Danelón. 2006. Effects of dairy cow diet forage proportion on duodenal nutrient supply and urinary purine derivative excretion. J. Dairy Sci. 89:3552-3562.

Mottram, T. 1997. Automatic monitoring of the health and metabolic status of dairy cows. Livest. Prod. Sci. 48:209-217.

Nagorcka, B. N., G. L. R. Gordon, and R. A. Dynes. 2000. Towards a more accurate representation of fermentation in mathematical models of the rumen. Pages 37-48 in Modelling nutrient utilization in farm animals. J. P. McNamara, J. France, and D. E. Beever, ed. CAB International, Wallingford, UK.

Neter, J., M. H. Kutner, W. Wasserman, and C. J. Nachtsheim. 1996. Applied Linear Statistical Models. 4th ed. McGraw-Hill/Irwin, Burr Ridge, IL.

Oldick, B. S., J. L. Firkins, and N. R. St-Pierre. 1999. Estimation of microbial nitrogen flow to the duodenum of cattle based on dry matter intake and diet composition. J. Dairy Sci. 82:1497-1511.

Rymer, C., and D. I. Givens. 2002. Relationship between patterns of rumen fermentation measured in sheep and in situ degradability and the in vitro gas production profile of the diet. Anim. Feed Sci. Technol. 101:31-44.

Shingfield, K. J., P. Salo-Väänänen, E. Pahkala, V. Toivonen, S. Jaakkola, V. Piironen, and P. Huhtanen. 2005. Effect of forage conservation method, concentrate level and propylene glycol on the fatty acid composition and vitamin content of cows' milk. J. Dairy Res. 72:1-13.

Shingfield, K. J., S. Jaakkola, and P. Huhtanen. 2001. Effect of forage conservation method, concentrate level and propylene glycol on diet digestibility, rumen fermentation, blood metabolite concentrations and nutrient utilisation of dairy cows. Anim. Feed Sci. Technol. 97:1-21.

Shingfield, K., S. Ahvenjärvi, V. Toivonen, A. Ärölä, K. V. V. Nurmela, P. Huhtanen, and J. Griinari. 2003. Effect of dietary fish oil on biohydrogenation of fatty acids and milk fatty acid content in cows. Anim. Sci. 77:165-179.

St-Pierre, N. R. 2001. Invited review: Integrating quantitative findings from multiple studies using mixed model methodology. J. Dairy Sci. 84:741-755.

St-Pierre, N. R. 2003. Reassessment of biases in predicted nitrogen flows to the duodenum by NRC 2001. J. Dairy Sci. 86:344-350.

Sutton, J. D. 1985. Digestion and absorption of energy substrates in the lactating cow. J. Dairy Sci. 68:3376-3393.

Sutton, J. D., M. S. Dhanoa, S. V. Morant, J. France, D. J. Napper, and E. Schuller. 2003. Rates of production of acetate, propionate, and butyrate in the rumen of lactating dairy cows given normal and low-roughage diets. J. Dairy Sci. 86:3620-3633.

Thomas, P. C., and P. A. Martin. 1988. The influence of nutrient balance on milk yield and composition. Pages $97-118$ in Nutrition and lactation in the dairy cow. P. C. Garnsworthy, ed. Butterworths, London, UK.

Ueda, K., A. Ferlay, J. Chabrot, J. J. Loor, Y. Chilliard, and M. Doreau. 2003. Effect of linseed oil supplementation on ruminal digestion in dairy cows fed diets with different forage:concentrate ratios. J. Dairy Sci. 86:3999-4007.

Van Nespen, T., B. Vlaeminck, W. Wanzele, W. van Straalen, and V. Fievez. 2005. Use of specific milk fatty acids as diagnostic tool for rumen acidosis in dairy cows. Comm. Appl. Biol. Sci. 70:277-280.

Vlaeminck, B., C. Dufour, A. M. van Vuuren, A. M. R. Cabrita, R. J. Dewhurst, D. Demeyer, and V. Fievez. 2005. Potential of odd and branched chain fatty acids as microbial markers: Evaluation in rumen contents and milk. J. Dairy Sci. 88:1031-1041.

Vlaeminck, B., V. Fievez, A. R. J. Cabrita, A. J. M. Fonseca, and R. J. Dewhurst. 2006a. Factors affecting odd and branched-chain fatty acids in milk: A review. Anim. Feed Sci. Technol. (accepted)

Vlaeminck, B., V. Fievez, D. Demeyer, and R. J. Dewhurst. 2006b. Effect of forage:concentrate ratio on fatty acid composition of rumen bacteria isolated from ruminal and duodenal digesta. J. Dairy Sci. 89:2668-2678.

Vlaeminck, B., V. Fievez, H. van Laar, and D. Demeyer. 2004. Prediction of rumen volatile fatty acid proportions produced in vitro using variations in rumen odd and branched chain fatty acids. J. Anim. Physiol. Anim. Nutr. (Berl.) 88:401-411.

Weimer, P. J., G. C. Waghorn, C. L. Odt, and D. R. Mertens. 1999. Effect of diet on population of three species of ruminal cellulolytic bacteria in lactating dairy cows. J. Dairy Sci. 82:122-134. 